British Journal of Psychiatry (1989), 155, 712-719

\title{
Correspondence
}

Editor: Ian Pullen

Contents: Fractured femurs in the mentally handicapped/US visas and 'insanity'/Doll phobia revisited/ Historical melancholia/ECT in old age/Pimozide in pathological jealousy/Syphilis screening/Lipopigment in the CNS/Tardive dystonia/Nicotine and dementia/Depression-dependent exacerbation of TD/Physical morbidity of psychiatric patients/ Benzodiazepines unabashed/Remission of psychotic symptoms after burn injury.

\section{Fractured femurs in the mentally handicapped}

SIR: Findings from the studies of Lau et al (1988) and Cooper et al (1988), on physical activity and calcium intake in fractures of the proximal femur in Hong Kong and in Britain, point to the fact that in order to protect against hip fractures it is important for elderly people to maintain daily physical activities and the required calcium intake.

We have completed a survey of the mentally handicapped population over 40 years of age in four hospitals in Bristol. There were 366 men and 365 women, of whom 55 men and 62 women sustained one or more fractures ( 72 and 110 fractures respectively). In the survey there were 36 fractures of the proximal femur (16 in men and 20 in women). Most of the patients with hip fractures were severely mentally handicapped and ages ranged from 44 to 77 years (mean age 57.3) in men and from 40 to 73 years (mean age 59.9) in women.

Apart from decreasing physical activity because of severe mental handicap and ageing processes, there were other factors which were impairing daily physical activities and mobility. Nine patients were on anticonvulsant therapy, eight were receiving antipsychotic drugs, two suffered from blindness, and eleven had debilitating physical disorders. The findings illustrate that decreased physical activity and mobility in the mentally handicapped is one of the risk factors for hip fractures in elderly patients.

It is therefore important that, with the marked increase in longevity of the mentally handicapped population (Carter \& Jancar, 1983), patients should continue with daily activities as long as possible, regular exercise should be encouraged, and calcium levels monitored, thus helping with protection against hip and other fractures.

Stoke Park Hospital

J. JANCAR

Stapleton

Bristol BS16 1QU

\section{References}

CARTER, G. \& JANCAR, J. (1983) Mortality in the mentally handicapped. A 50 year survey at the Stoke Park Group of Hospitals (1930-1980). Journal of Mental Deficiency Research, 27, 143-156.

COOPER, C., BARKER, D. J. P. \& Wickham, C. (1988) Physical activity, muscle strength, and calcium intake in fracture of the proximal femur in Britain. British Medical Journal, 297, 1443-1446.

LAU, E., Donnan, S., BARKER, D. J. P., et al (1988) Physical activity and calcium intake in fracture of the proximal femur in Hong Kong. British Medical Journal, 297, 1441-1443.

\section{US visas and 'insanity'}

SIR: There seems to be a widespread belief that compulsory admission under the provisions of the Mental Health Act 1983 adversely affects a person's ability to obtain a visa to enter the United States of America. We asked 16 mental health professionals (11 section-12 approved psychiatrists and 5 approved social workers) from two local hospitals how they thought mental illness and/or compulsory admission affected the ability of an individual to obtain a US visa: ten believed compulsory admission was the major factor, five were unsure, and one (a social worker) believed it was dependent upon the type of mental illness. Eight professionals said they would be less likely to detain a patient who wanted to obtain a US visa. We know of several recent cases in which the visa issue was considered important in deciding whether or not to detain the patient in hospital.

In order to clarify the situation, we wrote to the Visa Branch of the US Embassy who provided the following information: the US Immigration and Nationality Act stipulates that persons who are or have been 'insane' are ineligible for visas. However, the Attorney General can waive these ineligibilities and a person with a history of 'insanity' who is certified by a competent medical authority to be currently well may be granted a visa (visitor, temporary, or 
immigrant). Compulsory admission to mental hospital would serve as evidence of an attack of 'insanity' but the effect of such an admission would depend on the patient's recovery.

Thus, contrary to popular psychiatric belief, it appears that compulsory admission may, if it produces a more rapid recovery, actually help a patient to obtain a US visa.

Highcroft Hospital

Nick Craddock

Highcroft Road

Erdington

Birmingham B23 6AX

\section{Doll phobia revisited}

SIR: It was very interesting to read Hatcher's description of successful exposure treatment of a doll phobia in a 14-year-old boy (Journal, August 1989, 155, 255257). He notes the rarity of doll phobia despite the ubiquity of dolls in most cultures. Such discordance between frequency of contact with stimuli and fear of them may be partly explained by a prepotency and preparedness of certain cues to arouse fear more than others do in a species as a result of its evolutionary history. Incidentally, the credit for the first description of doll phobia probably goes to Rangell (1952), cited by Marks (1987, p. 396).

\section{Institute of Psychiatry \\ De Crespigny Park \\ Denmark Hill \\ London SE5 8AF}

ISAAC MARKS

Reference
MARks, I. M. (1987) Fears, Phobias and Rituals. New York: Oxford
University Press.
RANGELL, L. (1952) The analysis of a doll phobia. International
Journal of Psychoanalysis, 33, 43.

\section{Historical melancholia}

SIR: Berrios's (1988) conceptual history of melancholia and depression, while scholarly and deep, is, I would suggest, in parts overstated. He says, for example, that the concept of bipolar disease required a series of conditions that were only met after 1950 . Certainly earlier physicians spoke at the least of the continuity of melancholia and mania, for example Boerhaave (1728), Morgagni (1761), and Esquirol (1812) (see Frosch, 1987). Furthermore, it appears clear that the notion of alternating disturbed states of slow, exerted behaviour with fast, even frantic, behaviour can be seen to have entered the popular imagination. Caldwell (1972) has drawn our attention to the fact that the final movement of the sixth of the Opus 18 quartets (written in 1799) was entitled by Beethoven "La Malinconia". The movement consists of six alternating slow and fast sections, the slow sections inhibited, unelaborated, the fast sections bristling with energy, leaps and trill-like figures. That Beethoven recognised what he was portraying is confirmed in a later letter to a friend about another piece contemporaneous with "La Malinconia": "everyone at that time sensed ... the mental state of melancholia and its phases". That this notion was not new in 1800 can also be seen in Pondourus's description (fourth century AD) that mania is "an intermittent disease which proceeds through a periodical variant ... it repeats itself once a year or more often ... melancholia occurs in autumn, whereas mania in summer" (source of quote unlocated).

Good, careful observation is not a recent invention. While theory can determine what we are aware of seeing, through the millennia family and friends of individuals with manic-depressive disease must have been aware of its alternation, its circularity, aware of each phase's characteristic thought contents, feeling states, and activity patterns, aware of the continuity between the phases. The shamans and physicians involved in their care must also have known these facts. We should not delude ourselves that our unassisted senses and reasoning powers are better than those of our ancestors. Changing social structure and new data, real or imagined, lead to newly organised observations and to new explanations, to new theories. Berrios's paper properly directs us to this level of historical inquiry.

Department of Psychiatry

William A. Frosch

Cornell University Medical College

1300 York Avenue

New York, NY 10021

USA

\section{References}

Berrios, G. E. (1988) Melancholia and depression during the 19th century: a conceptual history. British Journal of Psychiatry. 153, 298-304.

CaldWell, A. E. (1972) La Malinconia: Final movement of Beethoven's quartet op. 18, no. 6: a musical account of manic depressive states. Journal of the American Medical Association, 27, 241-248.

Frosch, W. A. (1987) Moods, madness, and music. I. Major affective disease and musical creativity. Comprehensive Psychiatry, 28, 315-322.

\section{ECT in old age}

SIR: We read with interest the paper by Benbow on electroconvulsive therapy (ECT) for depressive 